\title{
Mechanical and Thermal Properties of Styrene-diene Block Copolymers Films Obtained by Spin Casting from Different Solvents
}

\author{
PAUL GHIOCA ${ }^{1 *}$, LORENA IANCU ${ }^{1}$, RAMONA MARINA GRIGORESCU1, RODICA-MARIANA IO N ${ }^{1,2}$, \\ MADALINA ELENA GRIGORE ${ }^{1}$, BOGDAN SPURCACIU ${ }^{1}$, RALUCA AUGUSTA GABOR ${ }^{1}$, CRISTIAN-ANDI NICOLAE ${ }^{1}$ \\ ${ }^{1}$ National Institute for Research \& Development in Chemistry and Petrochemistry - ICECHIM, 202 Splaiul Independenei, \\ 060021, Bucharest, Romania \\ ${ }^{2}$ Valahia University, Materials Engineering Department, $13^{\text {th }}$ Sinaia Alley, 130004, Targoviste, Romania
}

This paper presents the solvents effect on the mechanical and thermal properties of films of styrenebutadiene and styrene-isoprene block copolymers with the majority diene phase, obtained by spin casting.

Keywords: styrene-butadiene block copolymers, styrene-isoprene block copolymers, mechanical and thermal properties

Styrene diene (SDS) block copolymers are used in various application areas due to their high mechanical properties, easy processability, enabled by their thermoplastic behavior and, also by their low manufacturing cost [1]. This intense use is facilitated by the remarkable structural and compositional variation of the block copolymers, in particular styrene-butadiene (SBS) and styrene-isoprene (SIS), thus ensuring the most suitable properties for different uses [2].

According to the literature, the micro-phase structure of the polystyrene (PSt) phase dispersed in the majority continuous polydiene (PD) phase can be found in different forms, as spheres, hexagonal packed cylinders or alternating lamellas [3].

These structures are also influenced by the processing conditions, as for a styrene-butadiene block copolymer with $32 \%$ polystyrene obtained by spin casting from toluene, a lamellar structure is obtained, while a hexagonal cylindrical structure is achieved by extrusion due to the annealing during the process [4]. It has been established that there is a close correlation between these morphologies and the physical-mechanical properties corresponding to SDS block copolymers [5-10].

One of the most commonly used methods for varying SBS and SIS morphology consists in obtaining films by spin casting from different solvents [11-16].

In this paper, the effect of solvents with different solubility parameters on the mechanical and thermal properties of SBS and SIS block copolymers films obtained by spin casting from their solutions is presented.

\section{Experimental part}

In order to accomplish this study, a styrene-butadiene and a styrene-isoprene block copolymer, both with linear structure, were synthesized by sequential anionic polymerization of monomers in cyclohexane solution, initiated with n-butyl lithium, according to the methods described in the literature [17-20]. After the synthesis, the block copolymers were stabilized directly in the cyclohexane solution with $1 \% 2$, 6- di-tert-butyl-4methylphenol. The block copolymers were separated from the cyclohexane solution by desolvation with hot water and water vapors, and finally dried in air and in a vacuum oven at $60^{\circ} \mathrm{C}$.

The final molecular mass of block copolymers and of component blocks collected during synthesis was determined by gel permeation chromatography (GPC). The polystyrene content was confirmed by IR spectroscopy. The properties of the synthesized block copolymers are presented in table 1.

Table 1

STYRENE-BUTADIENE AND STYRENE-ISOPRENE BLOCK COPOLYMERS PROPERTIES

\begin{tabular}{|c|l|c|c|}
\hline Crt. No. & Property/Block copolymers & SBS & SIS \\
\hline 1. & Polystyrene content, \% & 31.80 & 30.70 \\
\hline 2. & Total molecular mass, g/mole & 100300 & 94800 \\
\hline 3. & Polystyrene block mass, g/mole & 15950 & 14550 \\
\hline 4. & Polybutadiene block mass, g/mole & 68400 & - \\
\hline 5. & Polyisoprene block mass, g/mole & - & 65700 \\
\hline
\end{tabular}

Five solvents were used to achieve the experiment: dioxane (1), dichloroethane (2), tetrahydrofuran (3), toluene (4), cyclohexane (5). Elastomer films of $1 \mathrm{~mm}$ thickness were obtained by spin casting from SBS and SIS solutions of 20\% concentration in these solvents [19-20].

The desolvation was carried out at $50-60{ }^{\circ} \mathrm{C}$, avoiding the thermal block copolymers degradation. Finally, the solvent traces were removed at $60^{\circ} \mathrm{C}$ in a vacuum oven. The polarity index is a measure of the relative polarity of a solvent and is useful for identifying the suitable interphase effects. The higher the polarity index is, the more polar the solvent is (table 2).

The tensile properties were determined using an FPZ100 dynamometer at $500 \mathrm{~mm} / \mathrm{min}$ elongation rate,

Table 2

THE SOLVENT POLARITY INDEX

\begin{tabular}{|c|c|c|}
\hline Crt. No. & Solvent & Solvent polarity index, P \\
\hline 1. & Dioxane & 5.27 \\
\hline 2. & Tetrahydrofuran & 4.0 \\
\hline 3. & Dichloroethane & 3.5 \\
\hline 4. & Toluene & 2.4 \\
\hline 5. & Cyclohexane & 0.2 \\
\hline
\end{tabular}


according to SR EN ISO 527-96, on type 2 specimens stamped from the obtained films. Investigation of thermal behavior was achieved by differential scanning calorimetry (DSC) and dynamic mechanical analysis (DMA).

Modulated temperature DSC determinations were performed on a DSC Q2000 (TA Instruments) apparatus, assisted by a liquid nitrogen cooling system (LNCS) in the temperature range of $-150 /-100^{\circ} \mathrm{C}$ to $+150^{\circ} \mathrm{C}$ using Tzero aluminium pans and helium (purity $99.999 \%$ ) as purge gas at a flow rate of $25 \mathrm{~mL} / \mathrm{min}$. Method: MDSC - heat only; Equilibrate to $-150{ }^{\circ} \mathrm{C} /-100{ }^{\circ} \mathrm{C}$, Modulate $\pm 1.592{ }^{\circ} \mathrm{C}$ every 30 s, Isothermal for $3 \mathrm{~min}, \mathrm{Ramp} 20^{\circ} \mathrm{C} / \mathrm{min}$ to $150^{\circ} \mathrm{C}$, Isothermal for $3 \mathrm{~min}, \operatorname{Ramp~} 20^{\circ} \mathrm{C} / \mathrm{min}$ to $-150^{\circ} \mathrm{C} /-100^{\circ} \mathrm{C}$, Isothermal for $3 \min$, Ramp $20^{\circ} \mathrm{C} / \min$ to $150^{\circ} \mathrm{C}$.

Dynamo-mechanical properties were determined using a DMA Q800 apparatus (TA Instruments) with Universal Analysis 2000 software results processing. Method: Temperature ramp, single frequency $1 \mathrm{~Hz}$, amplitude of 15 $\mu \mathrm{m}$, equilibrate to $-100^{\circ} \mathrm{C} /-70^{\circ} \mathrm{C}$, Isothermal for $3 \mathrm{~min}$, Ramp $5^{\circ} \mathrm{C} / \min$ to $150^{\circ} \mathrm{C}$.

The viscoelastic properties of the SBS/SIS films were investigated using dynamic mechanical analysis (DMA). DMA Q800 apparatus (TA Instrument Inc, USA) was used to measure the storage modulus, loss modulus and Tan Delta (Tan $\delta$ ) of each composite sample as a function of temperature. All samples were tested in the tension (film tension clamp) mode. The rectangular specimens (width $6 \mathrm{~mm}$, thickness $0.5 \mathrm{~mm}$, length $35 \mathrm{~mm}$ ) were heated after equilibration to $-100^{\circ} \mathrm{C} /-70^{\circ} \mathrm{C}$ (SBS/SIS) with a constant heating rate of $5^{\circ} \mathrm{C} / \mathrm{min}$ to $150^{\circ} \mathrm{C}$ and tested at a frequency of $1 \mathrm{~Hz}$ and amplitude of $15 \mu \mathrm{m}$.

\section{Results and discussions}

Styrene-diene block copolymers show at ambient temperature properties of vulcanized rubber due to the physical reticulation ensured by the PSt domains segregated in the PD continuous phase as a result of the thermodynamic incompatibility of the two blocks (polystyrene-polydiene) [18, 21, 22]. For the films obtained by relatively rapid evaporation of the solvent (about $3 \mathrm{~h}$ ) through spin casting, the separation of the two phases is not complete, existing also a transition zone where they are mixed [23-24]. The extent of this transition zone is strongly influenced by the solubility parameter of the casting solvent which controls its preferential affinity to one of the polymers.
Different values of the glass transition temperature $(\mathrm{Tg})$ of the polystyrene phase and of the polydiene phase (table 3) attest the incomplete separation of the two phases and thus the solvent affinity degree for the component phases of block copolymers can be determined.

The glass transition temperature for PSt phase decreases due to the presence of diene chains into its domains, while the contamination of PD phase with polystyrene blocks leads to a Tg increase of the elastomeric phase, as can be seen from the DMA diagrams (fig. 1, 2).

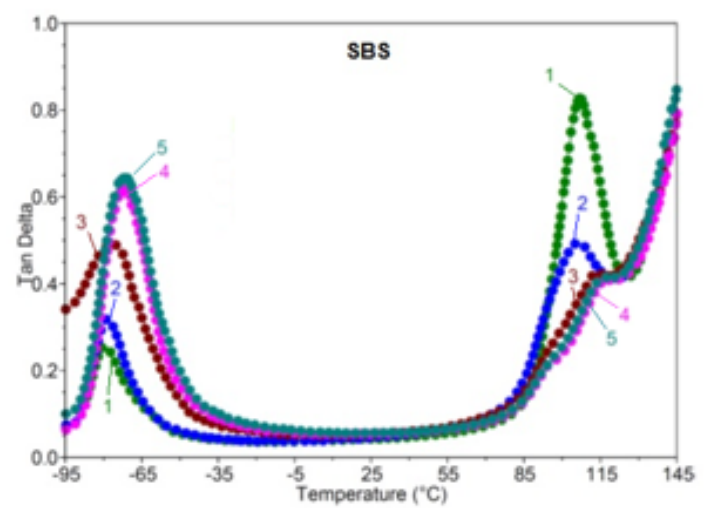

Fig. 1. DMA diagrams of SBS films obtained by centrifugal casting from different solvents: 1-dioxane; 2-dichlorethan,

3-tetrahydrofuran, 4-toluene, 5-cyclohexane.

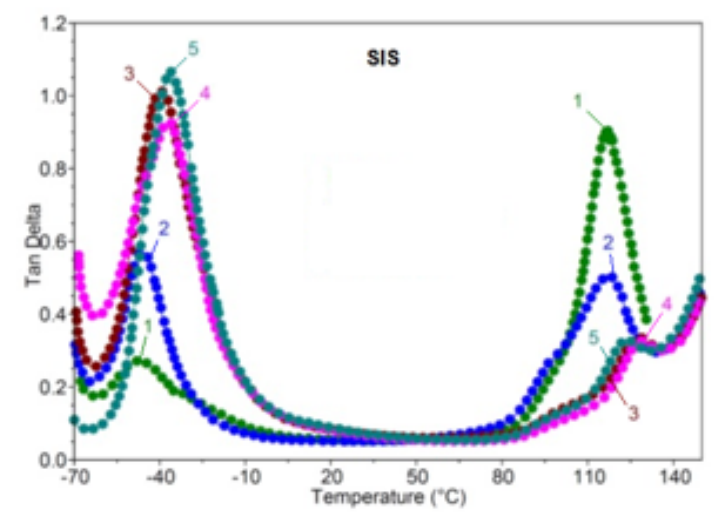

Fig. 2. DMA diagrams of SIS films obtained by centrifugal casting from different solvents: 1-dioxane; 2-dichlorethan, 3tetrahydrofuran, 4-toluene, 5-cyclohexane.

Table 3

PROPERTIES OF SBS AND SIS BLOCK COPOLYMERS OBTAINED BY SPIN CASTING FROM DIFFERENT SOLVENTS: DIOXANE (1), DICHLOROETHANE (2), TETRAHYDROFURAN (3), TOLUENE (4), CYCLOHEXANE (5)

\begin{tabular}{|c|c|c|c|c|c|c|c|c|c|c|c|}
\hline \multirow{2}{*}{$\begin{array}{l}\text { Crt. } \\
\text { No. }\end{array}$} & \multirow{2}{*}{$\begin{array}{l}\text { Properties / Block } \\
\text { copolymer }\end{array}$} & \multicolumn{5}{|c|}{ SBS } & \multicolumn{5}{|c|}{ SIS } \\
\hline & & 1 & 2 & 3 & 4 & 5 & 1 & 2 & 3 & 4 & 5 \\
\hline 1. & Tensile strength, $\mathrm{MPa}$ & 16.1 & 12.2 & 16.9 & 15.7 & 15.1 & 15.0 & 10.2 & 15.4 & 13.8 & 13.1 \\
\hline 2. & Elongation at break, $\%$ & 830 & 740 & 800 & 850 & 870 & 1380 & 1260 & 1320 & 1420 & 1500 \\
\hline 3. & Yield, MPa & - & 2.1 & 2.8 & 1.6 & - & - & 1.8 & 2.1 & 1.2 & - \\
\hline 4. & Hardness, 'ShA & 80 & 77 & 70 & 67 & 62 & 75 & 70 & 66 & 55 & 51 \\
\hline 5. & $\begin{array}{l}\text { Tg of polydiene block, } \\
{ }^{\circ} \mathrm{C} \text { (DSC) }\end{array}$ & -79.6 & -78.4 & -76.7 & -72 & -71.9 & -47.3 & -45.9 & -32.2 & -37.1 & -34 \\
\hline 6. & $\begin{array}{l}\text { Tg of polystyrene } \\
\text { block, }{ }^{\circ} \mathrm{C} \text { (DSC) }\end{array}$ & 95.3 & 92.6 & 92.2 & 95.2 & 91.7 & 96.1 & 96.8 & 97.9 & 99.4 & 96.4 \\
\hline 7. & $\begin{array}{l}\text { Storage modulus at } \\
30^{\circ} \mathrm{C}, \mathrm{MPa}\end{array}$ & 215.3 & 133 & 208 & 29.3 & 27.4 & 186.7 & 132.4 & 19.2 & 12.6 & 12.3 \\
\hline
\end{tabular}




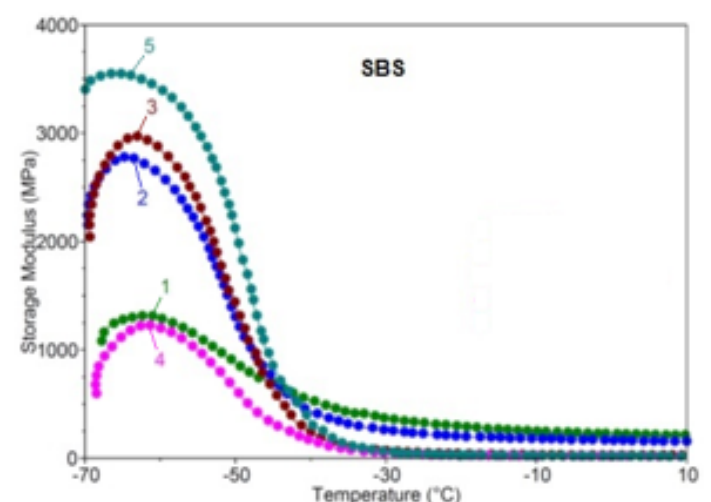

Fig. 3. Storage modulus at negative temperatures of SBS films obtained by centrifugal casting from different solvents: 1-dioxane;

2-dichlorethan, 3-tetrahydrofuran, 4-toluene, 5-cyclohexane.

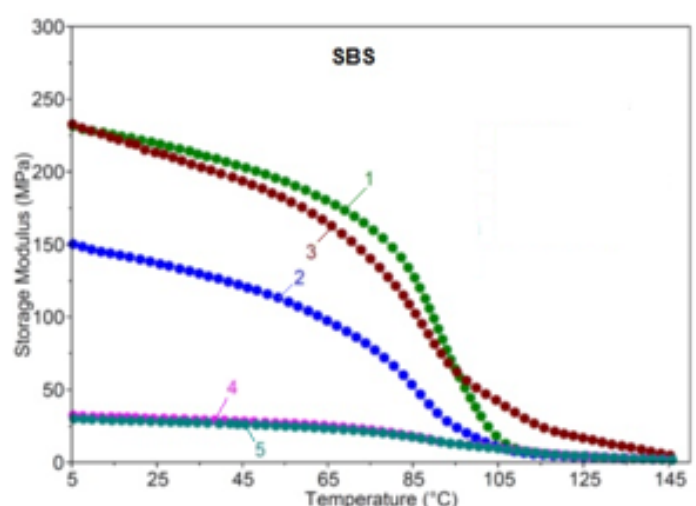

Fig. 4. Storage modulus at positive temperatures of SBS films obtained by centrifugal casting from different solvents: 1-dioxane;

2-dichlorethan, 3-tetrahydrofuran, 4-toluene, 5-cyclohexane.

In the polystyrene phase, the affinity of the solvent decreases in the order of: dioxane, dichloroethane, tetrahydrofuran, toluene, cyclohexane, this succession being determined by the Tg decrease for PSt phase. In the same order there is an increase in the affinity of the solvents for the diene phase. This order is correlated with the decrease of the solvent polarity index (table 2) and the $\delta$ solubility parameter: 10 for dioxane, 8.9 for toluene and 8.2 for cyclohexane. The different degree of PSt and PD phases separation influences the tensile behavior of block copolymers, as can be seen from table 3 .

The advanced separation of the polystyrene phase leads to an increase number of PSt blocks included in the plastomer domains, thus significantly increasing the crosslinking degree of the elastomeric phase. A higher crosslinking degree causes an increase of: tensile stress, tensile strength, storage modulus (fog. 3-6), and hardness and a decrease of the elongation at break (table 3).

It should be mentioned that although the block copolymers films have been obtained in the same heating regime, the solvent evaporation rate varies due to their different boiling temperature and volatility. It is known that the rate of evaporation influences the microstructure of the polystyrene phase $[2,11,25]$. Thus, in the case of spin casting from toluene at a slow evaporation rate, the polystyrene phase presents a double, cylindrical and lamellar morphology; at a medium evaporation rate a very ordered microstructure as cylinders in an hexagonal matrix is obtained; rapid evaporation of toluene leads to a disordered structure comprising all the three types of the polymeric phase: spheres, cylinders and lamellas. These polystyrene morphologies present a different interface in comparison to the polydiene matrix: three-dimensional for

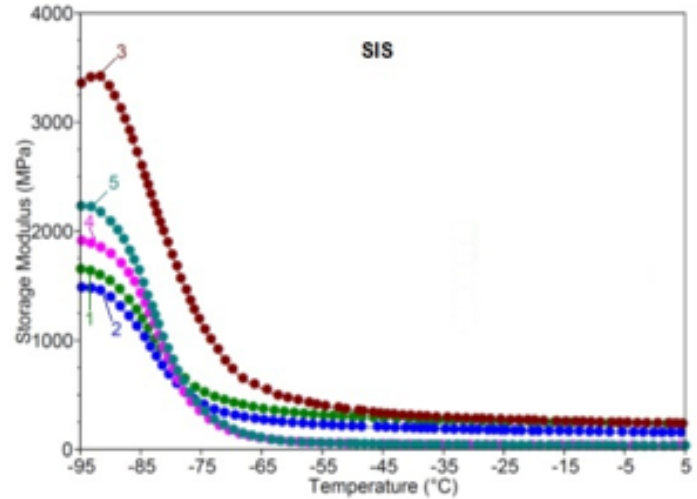

Fig. 5. Storage modulus at negative temperatures of SIS films obtained by centrifugal casting from different solvents: 1-dioxane; 2-dichlorethan, 3-tetrahydrofuran, 4-toluene, 5-cyclohexane..

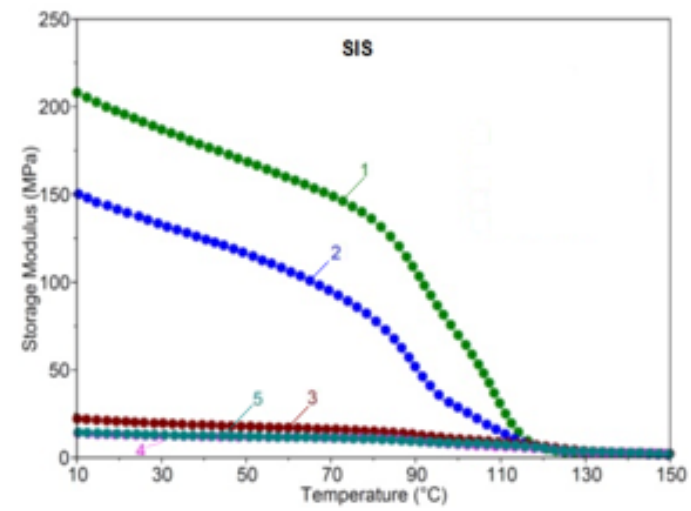

Fig. 6. Storage modulus at positive temperatures of SIS films obtained by centrifugal casting from different solvents: 1-dioxane;

2-dichlorethan, 3-tetrahydrofuran, 4-toluene, 5-cyclohexane.

the spherical domains, two-dimensional for the hexagonal domains and one-dimensional in the case of lamellar structure. These different polystyrene phase morphologies that ensure the physical crosslinking of styrene-diene triblock copolymers, participate with different contribution on the elastomer resistance subject to deformation and thus it is explained the variation of the mechanical properties (tensile strength, elongation at break, hardness) when the material is subjected to stretching (table 3 ).

It should be noted that the solvent effect used in the spin casting is similar for butadiene and isoprene block copolymers due to their close affinity degree to the solvents used in this study. Toluene was selected to be used in spin casting of styrene-diene block copolymers in order to eliminate the solvent effect on the physical-mechanical characteristics ensuring thus, at international level, a correct comparison of SDS properties manufactured by different companies. Even, the solvents with a higher $P$ favors certain mechanical properties (tensile strength, hardness) and thermal properties ( $\mathrm{Tg}$, storage modulus), nevertheless toluene is preferred as casting solvent because it is a nonselective solvent for polystyrene, polybutadiene and polyisoprene, respective [26-28].

\section{Conclusions}

The study of mechanical and thermal properties of SBS and SIS block copolymers with majority polydiene content obtained by spin casting showed that the solvent type predominantly influences the morphology of the polystyrene phase dispersed in the polydiene matrix. Modification of PSt morphology is correlated with the solvent affinity degree to polystyrene. 
Acknowledgements: This work was supported by a Nucleu Program, conducted with $\mathrm{MCl}$ support, project no. PN.18.22.04.02/2018 (PHOTOCAT), contractno. 21N/2018.

\section{References}

1.OVEJ ERO G., ROMERO M., DIEZ E., DIAZ I., Eur. Polym. J., 46, nr. 12, 2010, p. 2261.

2.FENG H., LU X., WANG W., KANG N.-G., MAYS J.W., Polymers, 9, nr. 10, 2017, p. 494.

3.XIA Y., CHEN J., SHI T., AN L., Chinese J. Polym. Sci., 31, nr. 9, 2013, p. 1249.

4.SAWYER L., GRUBB D.T., MEYERS G.F., Polymer microscopy: Springer Science \& Business Media, 2008, p.343.

5.MAMODIA M., PANDAY A., GIDO S.P., LESSER A.J ., Macromolecules, 40, nr. 20, 2007, p 7320

6.MAMODIA M., INDUKURI K., ATKINS E.T., DE JEU W.H., LESSER A.J ., J. Mater. Sci., 43, nr. 22, 2008, p.7035.

7.MIQUELARD-GARNIER G., HOURDET D., CRETON C., Polymer, 50, nr. 2, 2009, p.481.

8.CHONG H., TAYLOR A., J. Mater. Sci., 48, nr. 19, 2013, p.6762. 9.LIANG D., ZHOU L.-J ., ZHANG Q., CHEN F., WANG K., DENG H., FU Q., Chinese J. Polym. Sci., 30, nr. 4, 2012, p.603.

10.FU Z., GUI Y., CAO C., LIU B., ZHOU C., ZHANG H., J. Mater. Sci., 49, nr. 7, 2014, p.2864.

11.KIM G., LIBERA M., Macromolecules, 31, nr. 8, 1998, p.2569.

12. HUANG H., HU Z., CHEN Y., ZHANG F., GONG Y., HE T., Macromolecules, 37, nr. 17, 2004, p.6523.

13.J AMICSON R.T., KANISKIN V.A., OUANO A.C., SHEN M., in Advances in Polymer Science and Engineering edited by Pae K., Morrow D., Chen Y., Plenum Press, New York, 2012.
14.ZHOU Z., DOAK S., GRANDY D.B., ABRAMS K.J ., RODENBURG C., WESTON N., HURSTON D.J., Poster presented at The $16^{\text {th }}$ European Microscopy Congress, 2016, at Session Materials Science (MS 04-733). 15.SHIN J.M., KIM Y., YUN H., KIM B.J., ACS Nano., 11, nr. 2, 2017, p.2133.

16. HUH J., PARK C., in Manipulation of Nanoscale Materials, edited by Ariga K., ASC Publishing, 2012, p.53.

17.HSIEH H.L., QUIRK R., Anionic polymerization, Marcel Dekker, New York, 1996.

18.HOLDANG C., Thermoplastic Elastomers in Applied Plastics Engineering Handbook, Elsevier, Oxford U.K., 2011, p.77.

19.GHIOCA, P., IANCU, L., VULUGA, Z., SPURCACIU, B., GRIGORESCU, M.R., IORGA, M., FLOREA, D., Mat. Plast., 53, nr. 1, 2016, p.34.

20.GHIOCA ,P., GRIGORESCU, M.R., IANCU, L., SPURCACIU, B., NICOLAE, C.A., GABOR, A.R., Mat. Plast., 55, no. 1, 2018, p.14.

21.HOLDEN, G., LEGGE, N.G., SCHRODER, E., Thermoplastic Elastomers, Houser Publishers, Viena, 2006.

22.CRAVER C.D., CARRAHER C.E., Applied Polymer Science, Elsevier, N.Y., 2000.

23.HUY T.A., ADHIKARI R., MICHLER G.H., Polymer. 44, nr. 4, 2003, p.1247.

24.HUY T.A., ADHIKARI R., WEIDISCH R., MICHLER G.H., KNOLL K., Polymer. 44, nr. 4, 2003, p.1237.

25.MARK J.E., ERMAN B., FREDERIK E., Science and Technology of Rubber. Academic Press, N.Y., 1998.

26.DANESHFAR Z., GOHARPEY F., J. Polym. Res., 23, nr. 8, 2016, p.1. 27.DUAN Y., THUNGA M., SCHLEGEL R., SCHNEIDER K., RETTLER E., WEIDISGH R., SISLER H.W., STAMM M., MAYS J.W., HASYICHRISTIDIS N., Macromolecules, 42, nr. 2, 2009, p.4155.

28.ADHIKARI R., DAMM C., MICHLER G.H., MUNSTEDT H., BALTACALLEJA F.J., Compos. Interface, 15, nr. 5, 2008, p.453.

Manuscript received: 20.10 .2018 